\section{The dentist as expert}

\section{witness}

$\mathrm{T}$

WICE WITHIN THE SPAN of 2 years, I have been asked to act as an expert witness. Both cases involved the death of a patient in a dental office. Both of the deceased patients were individuals with significant mental deficiencies and physical disabilities, and both were being treated under circumstances that were routine for the settings in which the deaths occurred. Nevertheless, the patients died.

Most dental practitioners are, like myself, not used to providing legal testimony. So it was not surprising that "alarm bells went off" when the first attorney (for the plaintiff) phoned and requested that $I$ act in the capacity of an expert witness for his client. Two concerns immediately arose. "Should I even consider testifying?" and "How should I act?"

Consultation with my colleagues further confused the issue for me. Some said "don't," and others cautioned me to be prepared for a strong verbal assault from the defense. Less than comforted by this advice, I phoned the attorney and declined his invitation. He said dentists, like many physicians he had encountered, were a bunch of "cover-up artists," afraid to testify when a real injustice had been done. For those who consider themselves advocates for people with special needs, such an accusation is a blow to the conscience.

Here was a dilemma. We have all heard of dentists whose conduct made us blush on behalf of the profession. Is it fair to allow such individuals to continue unhampered, particularly when the victims are those that need special consideration? Yet doctors who choose to treat patients with special needs, those whose defenses may be severely compromised, are often faced with problems that are potentially life threatening for these individuals.

We are aware of how quickly a bad situation can develop. Our righteous indignation against injustice is quickly tempered by the consideration that we could find ourselves in the role of defendant. As it turned out, after I read transcripts of the cases and gave the opinion that what was done was not essentially different from what I believed should have been done, my involvement in the cases ended.
Several questions remain, however. Are there any quidelines for the dentist who is called on to be an expert witness and who wishes to respond in an ethical and responsible manner? What are the risks? The compensations? Indeed, there is a body of literature on the subject of the physician as an expert witness; much less exists for dentists, but new material is being published.

Complicating these questions is the fact that most states have their own rules regarding expert witnesses. How often are dentists called on to act in this capacity? Should a survey be conducted to determine the frequency? Should the membership of the Federation establish a cadre of qualified persons, such as some medical societies have done, that would provide impartial expert witnesses?

Our collective membership, after all, does contain experienced individuals who qualify as persons who have "special skill and/or knowledge in some particular field" (according to the definition of expert in the unabridged Random House Dic-

Our righteous indignation against injustice is quickly tempered by the consideration that we could find ourselves in the role of defendant.

tionary of the English Language, ed 2, 1987.) Perhaps a cadre would help discredit "experts" who are really charlatans, but who, I am told, testify nonetheless.

Can we do things to help establish standards rather than have them set for us, or should we not make the attempt? Perhaps the easiest course would be to turn our heads and hope the problem will go away, but somehow I don't think it will.

HENRY KANAR, DDS

Dr. Kanar is an associate professor of pediatric dentistry and onthodontics at the University of Michigan, Ann Arbor, and a member of the Editorial Board of Special Care in Dentistry.

Dr. Kanar thanks Brenda Harman, DDS, associate secretary, ADA Council on Insurance; Morris Friedman, LLB, of Moll, Desenberg, and Bayer, Detroit; and Ecrward Goldman, ID, University of Michigan, for their assistance and counsel. 